\title{
La verdad y la conjetura en La forma de las ruinas de Juan Gabriel Vásquez
}

\author{
Bibiana Fuentes/University of Wisconsin Eau Claire
}

\section{Resumen}

Este artículo discute la obra La forma de las ruinas de Juan Gabriel Vásquez. Analiza su uso de protocolos narrativos y sus implicaciones metaficcionales, filosóficas, literarias y éticas. Examina su relación intertextual con Jorge Luis Borges. Observa la relevancia y pertinencia de este texto dentro del diálogo político contemporáneo a su publicación. Argumenta que este texto hace un acercamiento a diferentes concepciones de la historia y su papel determinante en el impulso de fuerzas que motivan el actuar individual y colectivo. Al exponer diferentes concepciones del tiempo como teleológico, predeterminado por un plan divino, o contingente, la novela hace evidente la indeterminación de una verdad general frente al discurso de la historia.

Palabras claves: Historia colombiana, Jorge Eliecer Gaitán, Rafael Uribe Uribe, devenir histórico, Intertextualidad.

\begin{abstract}
This article discusses Juan Gabriel Vasquez's La forma de las ruinas, analyzes its use of narrative protocols and its metafictional, philosophical, literary, and ethical implications, observes the intertextuality with Jorge Luis Borges, and situates the text's relevance within political discussions contemporary to its publication. It argues that this text addresses different conceptions of history and their determinative role in motivating individual and collective action. By exposing different conceptions of time, such as teleological, predetermined by a divine plan, or contingent, the novel exposes the competing visions of history.
\end{abstract}

Keywords: Colombian history, Jorge Eliecer Gaitán, Rafael Uribe Uribe, historical becoming, Intertextuality.
Saturados por la incertidumbre de una guerra tan prolongada, un gran porcentaje de la población colombiana vive al margen del conflicto. El método de supervivencia ha sido concentrarse en su vida personal y tratar de olvidar un pasado que avergüenza y aterroriza. Al menos ese es el caso del narrador personaje de la novela La forma de las ruinas de Juan Gabriel Vásquez, publicada en 2016, quien después de vivir un tiempo en España regresa a Colombia para continuar escribiendo y disfrutar de un hogar apacible con sus dos hijas y esposa. Sin embargo, el pasado parece resentir ese olvido, irrumpe de manera violenta y se inmiscuye en el presente mediante la aparición de un objeto cargado de un magnetismo de reliquia, la vértebra donde se habría incrustado la bala que determinó la muerte de Jorge Eliecer Gaitán, político liberal cuyo asesinato el 4 de abril de 1948 "se convirtió en un suceso desequilibrador, después del cual no ha sido posible recuperar la estabilidad política en Colombia." (Banrepcultural) ${ }^{1}$ A partir de este hallazgo, el narrador se ve sobrecogido por un instinto atávico que le despierta una sensibilidad y atracción por los misterios que ese objeto encierra, lo cual desencadena un complejo y doloroso proceso de reflexión sobre el tiempo, el desarrollo de la historia y la pertinencia del pasado en la formación de nuestro presente.

En la novela el pasado adquiere un carácter virtual que se actualiza en el presente de una manera tan imprevista y violenta que sacude la tranquilidad de la cotidianidad generando un estancamiento del presente y un freno del impulso del porvenir. Esta irrupción permite reflexionar acerca de las diferentes y contradictorias concepciones sobre el carácter del devenir histórico que están presentes en el lenguaje cotidiano, especialmente, cuando se habla de la realización personal, el proyecto de vida y la visión como sociedad.

Sin ser conscientes de ello, repetimos frases en las que subyace una concepción teleológica de la historia como una línea cuya trayectoria tiene un objetivo o propósito. ${ }^{2}$ Esta concepción está en la base de la dialéctica hegeliana según la cual el pasado es el lugar de un conflicto superado y el presente la promesa de un porvenir que revelará los frutos del progreso. ${ }^{3}$ La historia se desarrolla en un proceso de constante negación que produce una posterior afirmación; por lo tanto, los conflictos históricos no son sino etapas de un proceso de depuración con un fin de perfeccionamiento. ${ }^{4}$ Hegel definió como ideal a alcanzar, a partir de la superación del caos de la historia, un estado global de razón universal, cuya cualidad sería la libertad: "la historia universal es el 
desarrollo de la conciencia, del espíritu de su libertad y de la efectivización de esa conciencia" (Hegel 2005, 151).

A partir de esta visión teleológica de la historia, algunas sociedades que se conciben a sí mismas como modernas identifican su propio telos, ya sea la superación de la injusticia, la búsqueda de la igualdad, el desarrollo de la razón, la ciencia, la tecnología, o como es el caso en la economía neoliberal la maximización de las ganancias de la empresa privada. Esta concepción subyace en los discursos que justifican la eliminación de algunos elementos por la posibilidad de un mundo más desarrollado que avanza hacia su potencialidad.

En el contexto socio-político de Colombia, especialmente en relación al momento coyuntural del acuerdo de paz con las FARC generado en 2016, año de publicación de la novela, esta concepción teleológica aparece en los discursos que prometen un futuro próspero, libre de los conflictos del pasado. ${ }^{5}$ El poeta y ensayista William Ospina en su libro De la Habana a la paz, publicado en 2016, nos ofrece un ejemplo de esta postura. El autor observa la opinión de algunos analistas según la cual existe una urgencia por dejar atrás el pasado doloroso y preparar lo más pronto posible un futuro amnésico, renacido y lleno de prosperidad; "a menudo oigo decir en las reuniones que analizan nuestro drama histórico que ya no podemos tener esperanzas en los hombres del presente, que hay que pensar en los hombres del futuro, los únicos que acaso tengan redención" (Ospina 2016, 16). Ospina analiza esta actitud como excluyente, en realidad, porque implica la perpetuación del señalamiento del otro y la negación de la propia responsabilidad. Aquellos que ven en los hombres del presente una causa perdida no se incluyen en ese grupo, no cuestionan su privilegio social y racial y su negativa a sacrificar lo que estructuralmente les ha sido dado y que consideran su derecho. Como si al cortar el tumor maligno de la insurgencia, el cuerpo social superara la enfermedad y alcanzara un mejor estado de salud. Sin ver el inconveniente lógico, se consideran a sí mismos elementos que construirán el futuro sin cambiar en absoluto los problemas estructurales del pasado y del presente. El curso de la historia, entonces, resulta, desde esta perspectiva, como una línea discontinua en la que se saldan las cuentas y se vuelve a comenzar desde cero. Es una visión optimista, y hasta cierto punto ingenua, ya que asume que la gente del futuro tendrá, a diferencia de la del pasado, un carácter y un actuar que evidencia que se avanza como sociedad.

Paralela a la confianza en el progreso existe una segunda concepción que considera que ese ideal ya ha sido alcanzado en el pasado, específicamente en la edad media, y que a partir de ese momento nos hemos ido alejando de ese lugar de perfección. Es una concepción que se impulsa en dirección contraria al discurso del progreso y que busca recapturar una perfección edénica. Aquellos abanderados de esta causa consideran que la modernidad ha alejado a los individuos cada vez más de los valores tradicionales, acercándolos al abismo de la destrucción. Es una visión que concibe la existencia de un plan divino predeterminado al que los individuos deben someterse. Se considera el presente no como la culminación positiva de la historia sino como una antítesis negativa que será superada cuando los patrones del pasado reemerjan en un futuro ideal; de allí su fuerza y motivación, ya que consideran su lucha fundamental para llegar más pronto a ese paraíso recuperado.

Jorge Andrés Hernández en su libro El último inquisidor, publicado en 2016, presenta como ejemplo de este pensamiento la Fraternidad Sacerdotal de San Pio X, fundada por Marcel Lefebvre en 1970, la cual se autodefine como una repuesta al cambio de orientación de la sociedad hacia el hombre en lugar de Dios. El historiador analiza la influencia de esta fraternidad en Latinoamérica y observa el proceso que se generó específicamente en Colombia, "de contra-reforma y de un modo más amplio de contra-ilustración, que perdura con matices hasta hoy" (Hernández 2016, 135). Esta tendencia ideológica ha influenciado el pensamiento de políticos como Alejandro Ordoñez, Procurador General de la nación entre 2009 y 2016, quien promulgó en su discurso un retorno de los valores tradicionales y la eliminación del estado laico. ${ }^{6}$

La novela La forma de las ruinas de Juan Gabriel Vásquez ilustra el rol determinante que tienen estas concepciones del devenir histórico en la formación de ciertas posturas radicales que han definido momentos claves de la historia colombiana. A través de este texto el autor propone que la memoria y la revisión histórica son temas recurrentes, pertinentes y hasta cierto punto urgentes en el panorama cultural y social del presente. La lectura de La forma de las ruinas sugiere varias preguntas: ¿Cuáles son las concepciones del devenir histórico que se presentan en esta novela? ¿Qué relación tienen con la aceptación o el rechazo a las transformaciones sociales? ¿De qué manera contribuye el texto literario a nuestra negociación con el pasado? En las siguientes páginas me propongo acercarme a algunas de estas preguntas, para ello discutiré los protocolos narrativos que utiliza la novela, los diferentes planteamientos en relación al rol de la literatura, la ilustración de las concepciones del devenir histórico, y su propuesta en relación a la memoria y la revisión histórica.

En La forma de las ruinas el escritor colombiano Juan Gabriel Vásquez se vale de la estrategia de la confrontación como protocolo narrativo para generar un diálogo sobre la historia de Colombia en el siglo XX. La voz narrativa es un escritor llamado Juan Gabriel Vásquez quien es además personaje actuante de esta novela y hace referencia a ciertos hechos que se podrían considerar autobiográficos en relación al autor, sin embargo, de aquí en adelante cuando utilice el nombre de Vásquez me referiré al personaje y no al autor. Así mismo, el autor crea el personaje de Carlos Carballo, un maniático de las teorías de la conspiración, quien le sirve 
de interlocutor y de contendiente intelectual al personaje de Vásquez.

Para hacer evidente la distancia entre estos dos personajes, la narrativa introduce a Carballo como un fanático ingenuo que cree que los hechos que presenta la ficción de Jorge Luis Borges y Gabriel García Márquez son literalmente tomados de la realidad, recurso conveniente mediante el cual se introduce la relación intertextual con estos autores, a lo cual un irritado Vásquez responde groseramente, "no sé si uno deba tomarse el párrafo suelto de un novelista como si fuera la verdad revelada. Por más García Márquez que sea" (Vásquez 2016, 61). La mención de Vivir para contarla de García Márquez contribuye a la contextualización de la novela misma como un texto que contiene elementos que fluctúan entre la anécdota, la biografía y la ficción, como si para hablar de la historia nacional se requiriera de algo más que los datos verificables del discurso historiográfico.

Así mismo "El pudor de la historia" publicado en Otras inquisiciones en 1952 y "Tema del traidor y el héroe," incluido en Ficciones 1944, de Jorge Luis Borges son intertextos fundamentales a nivel narrativo y filosófico. En "El pudor de la historia" el narrador observa como hechos relevantes al devenir histórico, personajes y fechas, pueden permanecer ocultos por mucho tiempo al no ser registrados por la historia oficial, "yo he sospechado que la historia, la verdadera historia, es más pudorosa y que sus fechas esenciales pueden ser, asimismo, durante largo tiempo, secretas" (Borges 1974, 754). Aquel que aprenda a observar estos hechos de la historia tendrá mayor posibilidad de intuir las profecías del futuro. En el teatro una estrategia para revelar esos hechos ocultos es la inclusión de un segundo actor, "con el segundo actor entraron el diálogo y las indefinidas posibilidades de la reacción de unos caracteres sobre otros" (Borges 1974, 755). Por lo tanto, la relación intertextual con este texto de Borges nos informa que en La forma de las ruinas el protocolo narrativo del contendiente tiene como objetivo poner en escena esta estrategia del diálogo entre dos personajes que hacen una lectura literal y figurativa de la historia. A través del diálogo se busca la revelación de esos hechos ocultos que iluminen el presente y el futuro.

Vásquez imagina a Carballo, "el seguidor de conspiraciones," leyendo "El pudor de la historia" y pensando en "fechas secretas más importantes que el 9 de abril de 1948, día de su obsesión malsana" (Vásquez 2016, 260). Luego, asume que al leer "Tema del Traidor y el héroe," Carballo ha entrado en un laberinto mental donde la historia es una repetición o combinación de "paralelismos que inducen a suponer una secreta forma del tiempo, un dibujo de líneas que se repiten" (Borges 1974, 497). Sin embargo, Carballo lo sorprende al aclararle que no se está adentrando en elucubraciones metafísicas; por el contrario, Carballo observa los paralelismos entre Rafael Uribe Uribe y Jorge Eliecer Gaitán y analiza que, aunque los actores no sean los mismos, Kilpatrick no fue Julio Cesar, al igual que Gaitán no fue Uribe, existe un monstruo que ha perpetrado a través de la historia cada uno de estos magnicidios,

Hablo de un monstruo, un monstruo inmortal, el monstruo de muchas caras y muchos nombres que tantas veces ha matado y matará otra vez, porque aquí nada ha cambiado en siglos de existencia y no va a cambiar jamás, porque este triste país nuestro es como un ratón corriendo en un carrusel. (Vásquez 2016, 539)

Este enunciado de Carballo sintetiza la motivación de toda la novela. Lo que se busca en más de 500 páginas es determinar quién es ese monstruo inmortal y cómo saltar fuera del carrusel. Para ello la narración tendrá que dar una vuelta por el pasado de la nación y adentrarse en la investigación del asesinato de Rafael Uribe Uribe en 1914, y en el de Gaitán en el 1948, para hallar de una vez por todas la identidad detrás de la figura sin rostro. ${ }^{7}$

Carballo cree completamente en la existencia de verdades ocultas detrás de los asesinatos de Uribe Uribe y de Gaitán. Verdades que no quedan en la historia oficial y que solo las mentes abiertas como la suya son capaces de entrever, "hay verdades que no son menos verdaderas por el hecho de que nadie las sepa. Tal vez ocurrieron en algún lugar raro adonde no pueden ir los periodistas ni los historiadores" (Vásquez 2016, 491). Premisa que resulta congruente con los comentarios del narrador de Borges en "El pudor de la historia." La falta de respuestas en el discurso de la historia y la impunidad alrededor de los crímenes lo obligan a buscar refugio en la literatura, como si esta tuviera el potencial de recuperar algo que ya se ha perdido. La narración, entonces, plantea el estatus privilegiado de la literatura en el discurso historiográfico como un instrumento de especulación histórica que contiene su propia verdad. Si la historia se ocupa de los hechos verificables, la literatura debe recrear aquello que no lo es, pero sin lo cual tendríamos una imagen más incompleta de la realidad.

Frente a los vacíos de la historia, a la literatura no le queda otro remedio que especular. Sin embargo, esto no es un inventar sin fundamento, no, la literatura se vale del archivo. Así como el padre de Francisco Benavides trata de resolver "crímenes celebres desde el punto de vista de la ciencia forense," (91) el escritor reconstruye las piezas de un rompecabezas incompleto con los bordes de los hechos corroborados, el contexto socio-político, los discursos del momento, las palabras de sus protagonistas y la cadena de consecuencias resultantes, desde el punto de vista particular de la literatura. No es una simple "reproducción novelada de los hechos verdaderos y comprobables," sino una exploración en "el reino de la posibilidad, de la especulación, o la intromisión que hace el novelista en lugares que le están vedados al periodista o al historiador" (Vásquez 2016, 205). La escritura ficcional es, entonces, exploración y desarrollo de una conjetura contextualmente posible. Para Caraballo, 
"sacar a la luz una conjetura es la labor más noble que puede llevar a cabo una persona. Desbaratar una mentira del tamaño de un mundo" (Vásquez 2016, 300), lo cual implica que la ficción no solo viene a ser un artefacto más de la historia, sino además tiene el potencial de desvirtuar la validez de hechos previamente no cuestionados.

La forma de las ruinas utiliza la misma estructura metaficcional de "Tema del traidor y el héroe" de Borges, al desarrollar dos niveles de lectura en la narración: el primero es el de la investigación, donde se hacen conjeturas frente a los autores de dos magnicidios, el segundo, el de la especulación, donde se hacen observaciones sobre los pensamientos, sentimientos y análisis de los investigadores. En "Tema del traidor y el héroe" el primer nivel introduce al investigador Ryan negociando con los vacíos de la historia oficial, "hay zonas de la historia que no... han sido relevadas aún; hoy... la vislumbro así" (Borges 2012, 177); y en un segundo nivel, el narrador extradiegético analiza las motivaciones y elucubraciones del investigador. El autor de La forma de las ruinas utiliza esta misma estructura. Ficcionaliza a Anzola, el autor de la investigación no oficial del magnicidio de Uribe Uribe, y crea a Carballo, un obsesionado de las conspiraciones, con quien Vásquez puede negociar las ideas de Anzola. ${ }^{8} \mathrm{Al}$ incluir estos dos niveles se enfatiza la lectura como elemento metaficcional. Vásquez, personaje, hace una lectura del texto de Anzola que le permite adentrarse en la investigación al mismo tiempo que se adentra en la psicología del investigador. Este texto, entonces, se ubica coherentemente dentro del género detectivesco latinoamericano; es una narración de un proceso de investigación que paralelamente se adentra en el carácter humano del detective al explorar sus pensamientos y sentimientos.

A la literatura le concierne la conciencia individual, por eso su especulación sobre el pasado se da desde adentro, desde los pensamientos y los sentimientos de aquellos protagonistas. Vásquez, por ejemplo, imagina lo que Anzola pudo haber pensado al encontrar la evidencia de un tercer asesino, "Anzola hubiera podido sentirse vindicado, pero se sintió triste. Se sintió solo" (Vásquez 2016, 309). Como explica el autor en una entrevista con Camila Pinzón, esta exploración del alma de los personajes es posible gracias a que la literatura es ese "lugar donde nadie intenta convencernos de nada, ese espacio único de libertad moral, emocional e ideológica" (Pinzón 2016, 1). La literatura explora un espacio negado a la historia, restringida por su demanda de evidencia verificable, el interior del individuo, su conciencia, su pensamiento, su alma.

Al especular sobre los pensamientos y acciones de Anzola, Vásquez no solamente construye subjetividades motivadas por su búsqueda de la verdad y su anhelo de justicia, además, expone todo un proceso de análisis de la evidencia no judicial, testimonios, rumores, opiniones, indicios, que en muchos casos revela los motivos e intereses de diferentes individuos. Información no verificable pero que resulta evidente gracias a la suma de indicios y a la ventaja que da el paso del tiempo y su vista retrospectiva.

En el caso del asesinato de Uribe Uribe, Vásquez analiza los elementos que llevan a Anzola a sacar sus conclusiones. ${ }^{9}$ A pesar de ser incapaz de proveer pruebas sobre la culpabilidad de individuos diferentes a Leovigildo Galarza y Jesús Carvajal, Anzola observa en las motivaciones de diferentes individuos que el magnicidio fue producto de una fuerza reactiva del campo social que requería a toda costa detener la fuerza de un movimiento de transformación que alteraría las estructuras presentes desde la colonia. Estas conclusiones resultan evidentes en documentos como periódicos, discursos del pulpito y testimonios de testigos. Para Anzola, resulta incontrovertible el odio por parte de los conservadores, quienes "se permitían uno que otro comentario ambiguo sobre las maneras que tiene Dios de escribir recto en renglones torcidos" (Vásquez 2016, 330). Así lo demuestra en las conclusiones que en 1917 publicara en su controversial texto Quiénes son?, según las cuales, los asesinos no serían otros que los conservadores radicales aliados con la iglesia y la policía:

El asesinato fue fraguado por ese grupo de conservadores carlistas... que seguramente continuará su serie de crímenes contra todo aquel que por sus condiciones superiores se coloque en situación de poner el país en marcha hacia la democracia y que el alma de esta torva y tenebrosa agrupación es la llamada Compañía de Sacerdotes Jesuitas. (Vásquez 2016, 416)

En sus conversaciones con Carballo, Vásquez advierte su total adherencia al análisis de Anzola; Carballo cree completamente en la existencia de esta fuerza reactiva, certidumbre que fundamenta en su análisis de los hechos previos y posteriores a los dos magnicidios. Si en algo se reflejan los dos asesinatos es en la obvia intransigencia que determina la polaridad política. Carballo observa la coincidencia de ofertas de tregua que son recibidas más como amenazas que como posibilidades de salir del conflicto. Por ejemplo, después de la derrota liberal de La Guerra de los Mil Días, Uribe Uribe apoyó al candidato conservador José Vicente Concha con el objetivo de llegar a una tregua política, dejar atrás los odios y contribuir a la construcción del país superando las diferencias bipartidistas, y es quizás esta decisión la que determinó su muerte.

Anzola observa el aislamiento y vulnerabilidad que esta actitud conciliatoria implicó para el general, "en la última década, Uribe Uribe, emblema del liberalismo más recalcitrante, había sufrido una metamorfosis que a sus partidarios les pareció escandalosa." Se había convertido en "el diplomático, el hombre de paz, cuya única obsesión era lograr la reconciliación del país" (Vásquez 2016, 265). La desconfianza sobre sus intenciones evidencia el nivel de radicalización que ya era evidente a principios de siglo, "Uribe era un 
propagador de doctrinas corruptoras y estaba condenado al fuego eterno como liberal; para la mitad de los liberales era un conservador, traidor a su partido y a su causa" (Vásquez 2016, 265). Además, frente a la posibilidad de compartir el poder, muchos conservadores se mostraron intransigentes, ya que si habían ganado la batalla militar lo consecuente sería la total eliminación del partido liberal.

Si La Guerra de los Mil Días había dado como vencedor al conservatismo era porque el espíritu de la historia había hecho justicia a los valores tradicionales y dado evidencia del plan de Dios. La victoria restablecía el Concordato firmado entre Rafael Reyes y la iglesia. ${ }^{10}$ Ejemplo de ello son las palabras de Fray Ezequiel Moreno Díaz, según el cual "el liberalismo es pecado, enemigo de Jesucristo, y ruina de los pueblos" (Vásquez 2016, 357). Anzola identifica este radicalismo en las palabras de los que celebran la muerte de Uribe Uribe en los periódicos católicos,

También entre nosotros hubo quienes pretendieron negar el rol sempiterno de la Santa madre Iglesia, violentar los valores tradicionales de nuestro pueblo y abrogar de manera unilateral el Concordato, fuente de nuestra perseverancia y guardián de nuestras conciencias, y que por eso Dios, que no castiga ni con palo ni con rejo, había hecho de ellos un lamentable ejemplo. (Vásquez 2016, 332)

Estas palabras le dan a Anzola la certeza de que gran parte de la sociedad colombiana había secretamente celebrado la muerte del general. "Para Anzola esa retórica era tristemente familiar...había muchos en Bogotá que se habían alegrado, considerando que el crimen de Uribe de Uribe no era un crimen, sino un castigo" (Vásquez 2016, 331). El odio y la intransigencia hacen que la guerra tienda a la intensificación; la paz, por el contrario, está sujeta a la contingencia y la más mínima acción puede destruirla. La radicalización de la sociedad que rechazó la tregua de Uribe Uribe provocó el incremento de la violencia, la guerra continuó, aunque sin ser nombrada, en los campos colombianos donde se siguió matando por filiación política.

En el Gaitanismo se dio un fenómeno similar, solo que la intransigencia alcanzó un extremo devastador. La ya famosa Marcha del Silencio constituía un llamado a detener el derramamiento de sangre en el país. ${ }^{12}$ Sin embargo, no era la solicitud de un pueblo que apela a su protector conservador, sino la exigencia de un movimiento consolidado que exhibe su capacidad de levantamiento y auto defensa. "Aquí están las grandes mayorías obedeciendo una consigna, dijo Gaitán. Pero estás masas que aquí se reprimen también obedecerían la voz de mando que les dijera: Ejerced la legítima defensa" (Vásquez 2016, 510). En estas palabras subyace una declaración de guerra que es correspondida con el asesinato del líder liberal.
La comparación de los dos subraya la relación causal de los dos hechos, sin embargo, el Gaitanismo como movimiento y la polarización política que lleva al asesinato de Gaitán no es exclusiva consecuencia de los hechos ocurridos en 1914, sino el producto de una serie de conflictos no superados por siglos. En la polarización ideológica y la identificación del enemigo subyacen estas dos concepciones del devenir histórico, una que busca superar los determinantes sociales que se asentaron en la colonia y otra que desea retornar a una distribución de poder exclusivamente entre las elites raciales y políticas, el ejército y la iglesia católica.

La investigación de Anzola y posterior lectura por parte de Vásquez identifica los argumentos morales, raciales, y económicos que motivan la intransigencia conservadora. Para aquellos que se fundamentan en una superioridad moral no existe posibilidad de ceder porque cualquier concesión significa abrirle la puerta al desorden, la impureza de sangre, fundamentalmente al demonio. Solo la victoria total, el exterminio del mal, es el único resultado aceptable. Para la elite política, social y militar, el odio apunta al rechazo visceral de la sublevación, no se puede tolerar que unos "indios," pobres, y desconocidos osen levantarse contra lo más natural.

La forma de las ruinas ficcionaliza las circunstancias que llevaron a la escritura de un libro. La narración revela el lento e indeciso proceso de alumbramiento casi abortado por la incredulidad del personaje de Vásquez. Todo este proceso se da a nivel intradiegético ya que gran parte de la narración tiene que ver con el acoso de Carballo a Vásquez: "No, Vásquez, a usted le hace falta compromiso, hermano, compromiso con las cosas difíciles de este país... ¿Se le mide a escribir el libro de su vida?... No deje pasar esta oportunidad" (Vásquez 2016, 156). Carballo trata de convencer a Vásquez que la suma de todos los documentos que él posee sobre los dos magnicidios revela una verdad no explicita en la historia oficial. Esta verdad, inverificable, resulta evidente para Carballo al observar fenómenos comunes en los dos magnicidios, como la complacencia de los entes de poder, estado, iglesia, y ejército, la condena de chivos expiatorios, la corrupción de la justicia, la impunidad, y la conjetura sobre la existencia de entes invisibles manipulando a los asesinos cuales maestros titiriteros. Es por ello que insistentemente acosa a Vásquez para que escriba la verdad que revele los mecanismos de una maquinaria política que ha sabido mantener impunes sus asesinatos gracias a la complacencia de una sociedad llena de odio y temor.

Vásquez, sin embargo, observa con cautela, y hasta cierta incredulidad, las conclusiones tanto de Anzola como de Carballo. Se niega en un principio a asumir este proyecto, no solo por su aversión por Carballo, sino porque aquello que subyace en sus obsesiones le resulta aterrador, la idea de ser objeto ignorante de una manipulación. De esta forma, la confrontación intelectual da lugar a una reflexión sobre la idea de la predeterminación de la historia. Carballo ve 
el devenir histórico manipulado por unas manos invisibles que nunca nadie conoce y frente a las cuales la sociedad se encuentra ignorante y por lo tanto impotente. Este pre-determinismo es absolutamente aterrador para Vásquez quien confía en su capacidad de autodeterminación. Vásquez ve la historia como una sucesión de hechos que ocurren accidentalmente, "yo vivía en un mundo así, irónico y escéptico, un mundo regido por el azar, el caos, los accidentes y las coincidencias" (Vásquez 2016, 538).

Esta discusión introduce una alternativa a la concepción teleológica del progreso y a la edénica del resurgimiento de la tradición; no existe objetivo ideal que se conseguirá en el futuro ni titiritero divino manejando los hilos del devenir histórico. Para Vásquez la historia es contingencia y el ser víctima de la violencia, una simple cuestión de azar. Carballo, sin embargo, le demuestra que aún si la historia es contingencia, eso no elimina el hecho que existan fuerzas poderosas que exacerben la virulencia del conflicto y que los autores detrás de la violencia estén motivados por una cierta concepción del devenir histórico.

Aún cuando Carballo no logra convencer completamente a Vásquez de sus hipótesis, sí consigue demostrar la validez de algunas conexiones entre los magnicidios y la literatura. A Vásquez le atrae especialmente la premisa que la literatura provee la formula fundamental de la conspiración. En el "Tema del traidor y el héroe," el investigador concluye que Shakespeare le ha proveído a Nolan los elementos para crear la puesta en escena del crimen de Kilpatrick. Carballo reconoce esta fórmula en los asesinatos de Uribe y Gaitán, y la utiliza para demostrarle a Vásquez la lógica de su especulación. Los diferentes documentos que dan testimonio de los hechos ocurridos en 1914 y 1948 son inconcluyentes cuando se observan por separado, pero cuando se observan en conjunto revelan la trama de un guión común a todos los magnicidios. Es evidente un proceso de producción en el que diferentes actores cumplen con un rol esencial, ya sea como víctimas, victimarios o testigos; el escenario es el centro social y político de la sociedad, "en medio de la calle concurrida" (Vásquez 2016, 11), y los hechos se desarrollan con exactitud de coreografía. ${ }^{13}$

En la tragedia se pone en escena un sacrificio cuyo resultado es la construcción de un mito que encarne los valores de una nación. Los mártires se entregan al papel que les corresponde en la tragedia. Teniendo conocimiento certero del inminente ataque actúan con cierta negligencia por su seguridad, su heroísmo radica en su negación a ceder en el objetivo de su causa. Vásquez reconoce la construcción de este arquetipo en la memoria del país, Gaitán, "el abogado de origen humilde que había llegado a las cimas de la política y estaba llamado a salvar a Colombia de sus propias élites despiadadas, es parte de nuestras mitologías nacionales" (Vásquez 2016, 25). La literatura, sin embargo, debe a su vez desmitificar al héroe y revelar que como ser humano tenía cierta flexibilidad moral según sus aspiraciones.
Vásquez, por ejemplo, descubre que Gaitán habría ganado un juicio gracias a una "manipulación grosera;" el abogado, "defensor de las libertades, [habría sacado] de la cárcel al asesino de un periodista" (Vásquez 2016, 34); sin que esto signifique la negación de su importancia histórica, "nunca he sentido la devoción incondicional que otros sienten por la figura de Gaitán, pero sé que este país sería un mejor lugar si no lo hubieran matado" (Vásquez 2016, 25). Al igual que Ryan, Vásquez no destruye la imagen positiva del político liberal.

Existe, sin embargo, una diferencia fundamental entre "El tema del traidor y el héroe" y La forma de las ruinas. A diferencia de lo que ocurre en Irlanda, el traicionado en Colombia es el pueblo. En el asesinato de Gaitán, los conspiradores se mantienen en el anonimato y manipulan el teatro popular para poner en situación de vulnerabilidad a los gaitanistas, cuya reacción no solo ayuda a su identificación, sino además justifica su exterminio. De esta forma el asesinato de Gaitán no es simplemente un magnicidio sino un genocidio político orquestado magistralmente por aquellos que vislumbraron su potencial.

Después de leer el texto de Anzola y escuchar el relato de Carballo sobre la muerte de su padre, Vásquez concluye que hay varias maneras de contemplar la historia, una de ellas es la contingencia, "la historia es el producto azaroso de una infinita cadena de actos irracionales, contingencias imprevisibles y hechos aleatorios." La otra es "la visión conspirativa," que asume la existencia de una fuerza reactiva detrás de unas "manos invisibles y ojos que espían y voces que susurran en las esquinas" (Vásquez 2016, 538). Esta segunda visión es la más aterrorizante porque implica la existencia de colectividades secretas que actúan fuera de toda moral manipulando los hilos del poder. Como la describe Anzola, una "fuerza tan grande capaz de que se convierta la verdad en mentira y que lo sucedido ya no haya sucedido;" garantiza que se absuelva a "los grandes lobos de la jauría" (Vásquez 2016, 383).

El personaje de Vásquez no pierde su fe en la contingencia, pero admite que su rechazo de las teorías conspirativas es "una estrategia inveterada para mejor lidiar con el caos de la historia y la revelación, ya mil veces probada, de que somos sus peones o sus marionetas" (Vásquez 2016, 538). Reconoce la existencia de esas fuerzas ocultas, cuya intolerancia es el resultado de una concepción del devenir histórico que identifica un telos que excluye a un porcentaje de la población. Vásquez además observa la ignorancia en la que vive la sociedad frente a la existencia de estas fuerzas. Deslumbrados con la tecnología, el urbanismo y la cultura del consumo los bogotanos consideran que han entrado finalmente en la modernidad. La polaridad virulenta entre los partidos políticos, la intolerancia basada en dogmas religiosos, el racismo y el clasismo, les parecen simplemente pensamientos retrógrados de algunos pocos. Sin embargo, "la ciudad [está] envenenada con el veneno de los pequeños 
fundamentalismos, y el veneno [corre] por debajo, como el agua sucia en las cloacas y los bogotanos [siguen]... creyendo que el veneno no existe" (204). ${ }^{14}$

Vásquez entiende la lógica de la teoría conspiratoria que observa Carballo, pero él no quiere escribir un texto como el de Anzola, cuyo supuesto objetivo es revelar la verdad sobre lo que realmente ocurrió. Vásquez sabe que ese tipo de verdad no le interesa a la literatura, como se plantea anteriormente, lo suyo es explorar, hacer una conjetura sobre aquello que no se encuentra en el discurso historiográfico. El relato de Carballo sobre el asesinato de su padre el 9 de abril por parte de francotiradores apostados en las azoteas es lo que finalmente convence a Vásquez de escribir la narración. La decisión responde a la motivación de especular sobre la vida de aquellos que han permanecido en el anonimato, aquellas victimas que no quedaron en los anales de la historia, "quería que las últimas dos horas de su padre quedaran documentadas tal como él las entendía, porque así su padre no solo tendría un lugar en el mundo, sino que habría jugado un papel en la historia" (Vásquez 2016, 539).

Para el narrador de "El pudor de la historia" resulta admirable el trabajo de aquel que recrea la memoria de un hecho del pasado, porque perpetua algo heroico. En $L a$ forma de las ruinas este honor le es concedido a Carballo, de ser patético termina al final reivindicado. La novela inicia con la imagen en la que es escoltado por la policía luego de romper la vitrina que contiene el traje de Jorge Eliecer Gaitán. Este es el enigma que introduce la novela, la causa que ha llevado a este personaje a cometer esta trasgresión. Al final resulta evidente que la escritura del libro implica para Carballo la posibilidad de hacer duelo por la muerte de su padre. Como acto que satura la herida, acude al museo para tocar el último lugar donde se posó la mano de su padre. Se cierra el círculo narrativo al evidenciar el carácter retrospectivo de la narración y enfatizar el acto de escritura.

En relación a su conflicto con el pasado y el ejercicio de revisión histórica Vásquez comprende que el 9 de abril sigue atormentando a los colombianos no solo porque continúa impune sino, además por ser, "una neurosis colectiva que nos ha servido para desconfiar de nosotros mismos durante más de medio siglo" (Vásquez 2016, 25). Cada colombiano ha heredado los crímenes, el odio, la culpa, y una cuota de responsabilidad histórica. En el caso de Vásquez, su parentesco con José María Villareal y su crianza en una familia estrictamente conservadora le ha heredado una visión, culpa y miedo particular. ${ }^{15}$ Si para Carballo el libro supone una forma de duelo, para Vásquez acarrea el dejar de evadir el fantasma que lo acecha desde joven. Caraballo se cruza en su vida para poner en marcha "una maquinaria de espanto" que obliga a Vásquez a revisitar el pasado y escribir el libro "como expiación de crímenes que, aunque no [ha] cometido, [ha] acabado por heredar" (Vásquez 2016, 16).
Nuestras violencias no son solamente las que nos tocaron en vida, sino también las otras, las que vienen de antes, porque todas están ligadas, aunque no sean visibles los hilos que las unen, porque el tiempo pasado está contenido en el tiempo presente, o porque el pasado es nuestra herencia sin beneficio de inventario y al final lo acabamos recibiendo todo: la cordura y las desmesuras, los aciertos y los errores, la inocencia y los crímenes. (Vásquez 2016, 189)

Se concluye que dentro de esta maquinaria narrativa, el protocolo narrativo del contendiente intelectual, el doble, la otra cara del protagonista, en este caso el personaje de Carba1lo, funciona con varios propósitos. A nivel metaficcional da lugar a la reflexión sobre el estatus de la literatura frente a la historia. A nivel filosófico, introduce una visión alternativa a la teleológica de la historia marcada por la contingencia y la influencia de fuerzas en constante enfrentamiento. A nivel literario, hace una especulación sobre las motivaciones que rodearon los magnicidios. A nivel ético, argumenta la inescapable responsabilidad de cada colombiano con la herencia histórica.

A nivel intradiegético la literatura contribuye al discurso de la historia. El diálogo con el contendiente da como resultado un texto en el que Vásquez especula y desarrolla, a través de la investigación y de manera contextual, una conjetura sobre lo que pudo ser la vida de un militante del partido liberal, seguidor de Gaitán, quien fuera asesinado el 9 de abril de 1948. La historia oficial, incluyendo los elementos que se encuentran en los libros y museos, ofrece una imagen incompleta de lo que sucedió ese día, al explorar la posibilidad de un personaje como el padre de Carballo, especular sobre su vida, sus relaciones y motivaciones, Vásquez haría entrar en el discurso de la historia a uno que representa a la masa anónima que murió ese día,

Fui llenando página tras página de memorias como estas, de notas y de datos, en el intento desesperado de transfigurarlos por medio de la imaginación, que todo lo ilumina, y de la fábula, que ve más lejos que nosotros, y así entender por fin lo sucedido durante esta década: entender los hechos públicos y visibles, por supuesto, las legiones de imágenes y relatos que nos aguardaban en las crónicas y la historiografía..., pero también entender los hechos invisibles y privados, que no están contenidos en ninguna parte porque ni el mejor de los historiadores, ni el mejor de los periodistas, puede contar lo que ocurre en el alma del otro. (Vásquez 2016, 188)

La forma de las ruinas sirve como medio de confrontación y expiación dentro de la diégesis y como producto cultural. Dentro de la narración Vásquez debe tomar en sus manos, metáfora recurrente en la novela, ese pasado heredado, analizarlo y entenderlo, a pesar del horror 
que encierra, para así podérselo entregar a sus hijas de una manera menos traumática y más consciente de lo que lo hicieron sus antepasados. Como producto cultural esta novela contribuye a la confrontación del monstruo sin rostro, ese huracán de fuerzas en disputa entre los que plantean el imperativo de una transformación social que traiga la justicia social al país, el empleo digno, la distribución de la tierra, la reivindicación de las minorías; y aquellos que ven en peligro sus antiguos privilegios, la propiedad privada, y que luchan bajo la bandera de la moral, la tradición, la familia y la fe.

En respuesta a las preguntas planteadas al inicio de este ensayo sobre las concepciones del devenir histórico que se presentan en esta novela y su relación con la aceptación o el rechazo a las transformaciones sociales se dan las siguientes conclusiones:

La Forma de las ruinas observa cómo diferentes individuos e instituciones sociales y políticas plantean la concepción del devenir histórico que más se ajusta a sus intereses como verdad universal para justificar su ejercicio de poder. La virulencia de la confrontación en el siglo XX y el presente se debe a la incapacidad de identificar un telos que incluya de manera justa a toda la población. La intransigencia de los actores históricos es el síntoma de la incompatibilidad entre la visión de un futuro que rompa con la tradición y transforme las estructuras sociales y otro en el que se reivindiquen esas mismas estructuras y dogmas. Aún aquellos que se apartan de las ideologías y rechazan estas concepciones teleológicas, considerando el devenir histórico como contingencia y azar, no pueden evitar ser confrontados por un pasado que les demuestra la prevalencia de ciertas fuerzas que ejercen influencia sobre los acontecimientos que afectan a toda la nación.

La Forma de las ruinas cumple con la función de exponer la indeterminación de una verdad universal sobre la historia. Al exponer diferentes concepciones del tiempo como teleológico, predeterminado por un plan divino, o contingente, la novela hace evidente la indeterminación de una verdad general frente al discurso de la historia. De esta manera, la novela contribuye a una lectura crítica de los discursos políticos e ideológicos. Al eliminar la infalibilidad de una única concepción se abre la posibilidad de observar críticamente los prejuicios raciales, de género y clase que subyacen en las dinámicas de poder. De esta manera se abren grietas en los modelos que determinan la adquisición de una afiliación política basada en verdades universales.

A nivel extradiegético La forma de las ruinas es una novela que dialoga con el discurso histórico. Evidencia de ello es la coincidencia de argumentos planteados en textos anteriormente citados, De la Habana a la paz de William Ospina (2016) y El último inquisidor de Jorge Andrés Hernández (2014), en relación a una permanente reactivación de fuerzas en pugna. William Ospina, por ejemplo, describe el estado actual como "una olla de presión... en una sociedad frenada en sus impulsos sociales y en su capacidad de creación", e identifica a 1948 como el año en que se aplicó definitivamente el freno a cualquier reforma, dejándonos en "esa olla de presión que produce violencia, desesperación y desaliento en todos los órdenes de la vida, donde el esfuerzo por ser ciudadano, por trabajar, por construir una sociedad de convivencia, es algo que hay que hacer contra la corriente" (Ospina 2016, 304). Jorge Andrés Hernández, mientras tanto, identifica un delirio reaccionario por parte de los defensores de la tradición. Se refiere a aquellos liderados por el exprocurador general Alejandro Ordóñez, para quienes la historia se equivocó al montarse en el tren del progreso y el liberalismo, creyentes fervientes del peligro de la modernidad y que luchan por poner freno al total desprendimiento del hombre de lo que ellos consideran lo natural. Se puede concluir, por lo tanto, que la lucha no se supera ni se sintetiza con el paso del tiempo, fuerzas reactivas continúan influyendo nuevos individuos que ejercen su poder de acuerdo a concepciones aprendidas del devenir histórico.

Resulta fundamental, entonces, si se quiere salir del carrusel como lo denomina Carballo, primero, una consciente confrontación con el pasado que ayude a entender la violencia del pasado, y segundo, ceder algo de nuestro privilegio y resentimiento para darle al país la oportunidad de reinventarse. La sociedad colombiana debe, además de dar espacio a las transformaciones sociales, cuestionar críticamente los discursos políticos que excluyen a una parte de la población mediante concepciones teleológicas y dejar florecer la cultura colombiana en su estética idiosincrática sin la anulación prejuiciosa que motivan sus odios heredados.

\section{Notas}

1. “Jorge Eliecer Gaitán” Enciclopedia Banrepcultural, encontrado en enero 20, 2018, http://enciclopedia.banrepcultural.org/ index.php?title=Jorge Eli\%C3\%A9cer_Gait\%C3\%A1n

2. La etimología de este término viene del griego télos que significa "meta", "fin", "propósito", y logos que es "explicación" o "razón".

3. Las citas que se presentan a continuación son tomadas de lecturas compiladas después de la muerte de Georg Hegel publicadas en 1837 bajo el título Lecciones sobre la filosofía de la historia universal. Uso la edición de Tecnos con traducción de José Gaos. En este texto se relaciona el concepto del espíritu de los pueblos y la historia universal y se argumenta que este espíritu se configura y progresa a través del tiempo: "La variación abstracta que se verifica en la historia ha sido concebida, 
desde hace mucho tiempo, de un modo universal, como implicando un progreso hacia algo mejor y más perfecto... El hombre tiene una facultad real de variación que camina hacia algo mejor y más perfecto, obedece a un impulso de perfectabílidad... Es esencial advertir que el curso del espíritu constituye un progreso... Esta determinación formal es esencial; el espíritu que en la historia universal tiene su escenario, su propiedad y el campo de su realización, no fluctúa en el juego exterior de las contingencias, sino que es en sí lo absolutamente determinante; su peculiar determinación es absolutamente firme frente a las contingencias que el espíritu domina y emplea en su provecho" (Hegel 2015, 211).

4. "Pero aun cuando consideremos la historia como el ara ante el cual han sido sacrificadas la dicha de los pueblos, la sabiduría de los estados y la virtud de los individuos, siempre surge al pensamiento necesariamente la pregunta: ¿a qué fin ultimo ha sido ofrecido este enorme sacrificio? Estos son los medios, la determinación sustancial, el fin ultimo absoluto, lo que es lo mismo, el verdadero resultado de la historia universal" (Hegel 2005, 145).

5. Después de medio siglo de confrontación y cuatro años de negociación en La Habana, Cuba, el gobierno colombiano y la guerrilla de las FARC llegaron a un acuerdo para terminar la guerra. El 26 de septiembre de 2016 el presidente de turno, Juan Manuel Santos, y el máximo jefe de esta guerrilla, Rodrigo Londoño Echeverri, 'Timochenko' firmaron el Acuerdo Final de Paz. Para información sobre el contenido del acuerdo visite el siguiente enlace: http:/www.altocomisionadoparalapaz.gov.co/ herramientas/Documents/Acuerdo-Final-AF-web.pdf.

6. Alejandro Ordoñez, destituido procurador, se opuso desde la Procuraduría a los derechos igualitarios de la comunidad LGBTI, al aborto en casos excepcionales y al derecho a una muerte digna. Para información sobre el contenido de sus propuestas visite el siguiente enlace: http://www.eltiempo.com/justicia/cortes/alejandro-ordonez-peleas-28815.

7. Rafael Uribe Uribe fue un jurisconsulto, orador, militar, periodista y diplomático colombiano. Ideólogo liberal que luchó en la Guerra de los Mil Días. Después de la derrota en la guerra fue jefe del partido liberal y promotor de la paz. Fue asesinado el 15 de octubre de 1914 frente al Capitolio Nacional.

8. ¿Quiénes son? es un texto publicado en Bogotá en 1917 por el abogado Marco Tulio Anzola Samper sobre el asesinato del general Uribe Uribe.

9. El texto nuevamente revela su proceso de producción al ficcionalizar el proceso de investigación y negociación que el autor ha desarrollado con el texto de Anzola. "Se titula ¿Quiénes son?, escrito por Anzola Samper, que descubrí más o menos por azar y que me sorprendió porque ni yo, ni tanta gente con la que siempre he hablado del tema, habíamos sabido de él... Ese libro lo digitalizó la Biblioteca Luis Ángel Arango y, con un poco de maña, es posible encontrarlo. Yo tuve el original en mis manos, pero como existe un solo ejemplar no se puede sacar de la biblioteca". El autor Juan Gabriel Vásquez en una entrevista con Margarita Vidal.

10. "Concordato entre La Santa Sede y la República de Colombia" es el título del texto firmado por el presidente conservador Rafael Reyes y la iglesia católica en 1887, según el cual "La Religión Católica, Apostólica y Romana, es la de Colombia." Para información sobre el contenido del concordato visite el siguiente enlace: https://www.cec.org.co/sites/default/files/ WEB_CEC/Documentos/Documentos-Historicos/1973\%20Concordato\%201887.pdf.

11. En respuesta a este ataque del padre Ezequiel Moreno, Rafael Uribe escribió el texto "De cómo el liberalismo político colombiano no es pecado." "Uribe alegaba que el Partido Liberal era tan católico como el otro, tan respetuoso como el otro de las instituciones familiares y sociales que informaban la vida colombiana, y enseguida animaba a los liberales colombianos a enfrentarse a los abusos del clero, denunciarlos y condenarlos" (Vásquez 2016, 375).

12. 17 de febrero de 1948, el caudillo Jorge Eliécer Gaitán convocó a una manifestación por la paz que fue conocida como La Marcha del Silencio.

13. Una parte sustancial de la novela se concentra en las obsesiones que motivan la búsqueda de documentos sobre importantes magnicidios. Benavides, doctor que presentará a los dos protagonistas, le habla a Vásquez sobre el archivo que llevara su padre sobre el asesinato de John F Kennedy, con el objetivo de demostrarle que aquello que obsesiona a Carballo no es simplemente la idea de una conspiración, sino la existencia de una fórmula común a los magnicidios y evidente al observar los diferentes indicios que contiene el archivo. Fórmula que evidencia la imposibilidad de la hipótesis del asesino solitario frente a la certeza de la existencia de una fuerza reactiva que impulsa el actuar de una colectividad secreta.

14. La novela ilustra un proceso de transformación en la relación de Vásquez con Bogotá, ya que desde el principio de la narración "la ciudad asesina, la ciudad cementerio, la ciudad donde cada esquina tiene su caído," le produce fascinación y rechazo visceral. En sus años universitarios deambula por las calles "persiguiendo a los fantasmas de los muertos de una muerte violenta justamente por miedo de ser un día uno de ellos" (Vásquez 2016, 42). Luego de intentar escapar de la ciudad y su pasado, vuelve a ella y es el encuentro con Carballo lo que le confiere un análisis más crítico, menos morboso, sobre lo que determina el carácter violento de la misma. 
15. A nivel intradiegético, Carballo se interesa por Vásquez en un principio precisamente por su parentesco con José María Villareal, gobernador de Boyacá en 1948, quien enviara mil hombres uniformados a la capital del país para ayudar a controlar a la muchedumbre enfurecida por el asesinato de Jorge Eliecer Gaitán. Por ello Carballo le replica "estamos hablando de lo más grave que le ha pasado a su país y a usted parece que no le importara... Sabe muy bien que su tío organizó la Policía boyacense. Sabe muy bien que esa Policía se convirtió después en una Policía asesina" (Vásquez 2016, 62). Este además de ser un elemento intradiegético importante en la confrontación de estos dos personajes es un referente autobiográfico del autor. Las conclusiones que se presentan en este ensayo sobre las motivaciones de escribir el texto se limitan, sin embargo, al campo intradiegético, aún cuando supongamos que el autor Juan Gabriel Vásquez tuviera estas mismas motivaciones al escribir la novela.

\section{Obras Citadas}

Borges, Jorge Luis. 1974. Obras completas. Buenos Aires: Emece Editores.

Hegel, Georg. 2005. Lecciones sobre la filosofia de la historia universal. Madrid: Editorial Tecnos.

Hernández, Jorge Andrés. 2014. El último inquisidor. Bogotá: Ediciones B.

Ospina, William. 2016. De la Habana a la paz. Bogotá: Debate Editorial.

Pinzón, Camila. 2016. "El novelista como historiador de las emociones." En El Espectador, 11 de febrero, 2016. Consultado el 30 de junio, 2017. https://www.elespectador.com/noticias/cultura/el-novelista-historiador-de-emociones-articulo-616005.

Vásquez, Juan Gabriel. 2016. La forma de las ruinas. Bogota: Alfaguara.

Vidal, Margarita. 2016. “Juan Gabriel Vásquez: Su reputación lo precede.” En Revista Credencial, 5 de mayo, 2016. Consultado el 30 de junio, 2017. http://www.revistacredencial.com/credencial/noticia/libros/juan-gabriel-vasquez-su-reputacion-loprecede. 